Article

\title{
Influences of Post-Heat Treatment on the Microstructure Evolution and Creep Properties of Ni-Based Superalloy IN718 Fabricated by Electron Beam Melting
}

\author{
Thaviti Naidu Palleda ${ }^{1, * \mathbb{D}}$, Santhosh Banoth ${ }^{1}$ (D), Yen-Ling Kuo ${ }^{2}$ and Koji Kakehi ${ }^{1, *(D)}$ \\ 1 Department of Mechanical Systems Engineering, Tokyo Metropolitan University, 1-1, Minami-Osawa, \\ Hachioji-City, Tokyo 192-0397, Japan; banoth-santhosh@ed.tmu.ac.jp \\ 2 Department of Mechanical Engineering, Nagaoka University of Technology, 1603, Kamitomioka, \\ Niigata 940-2188, Japan; kuo@vos.nagaokaut.ac.jp \\ * Correspondence: palleda-thaviti-naidu@ed.tmu.ac.jp (T.N.P.); kkakehi@tmu.ac.jp (K.K.); \\ Tel.: +81-080-9533-5898 (T.N.P.); +81-426-771-712 (K.K.)
}

check for

updates

Citation: Palleda, T.N.; Banoth, S.;

Kuo, Y.-L.; Kakehi, K. Influences of Post-Heat Treatment on the Microstructure Evolution and Creep Properties of Ni-Based Superalloy IN718 Fabricated by Electron Beam Melting. Metals 2022, 12, 446.

https://doi.org/10.3390/ met12030446

Academic Editors: Katrin Wudy and Peter Mayr

Received: 24 January 2022

Accepted: 1 March 2022

Published: 4 March 2022

Publisher's Note: MDPI stays neutral with regard to jurisdictional claims in published maps and institutional affiliations.

Copyright: () 2022 by the authors. Licensee MDPI, Basel, Switzerland. This article is an open access article distributed under the terms and conditions of the Creative Commons Attribution (CC BY) license (https:// creativecommons.org/licenses/by/ $4.0 /)$.

\begin{abstract}
In this study, the Ni-based superalloy IN718, fabricated using an electron beam melting process, was investigated in as-built and various heat-treated conditions. The relationships between the microstructure characteristics and creep properties were elucidated. Under testing conditions of $650{ }^{\circ} \mathrm{C}$ and $650 \mathrm{MPa}$, the direct-aged specimen exhibited the lowest steady-state creep rate, at $0.15 \times 10^{-8} \mathrm{~s}^{-1}$. The superior creep resistance can be attributed to the higher volume fraction of $\gamma^{\prime} / \gamma^{\prime \prime}$-strengthening precipitates within the grain and fine $\delta$ precipitates along the grain boundaries. Being coherent to the $\gamma$ matrix, the nano-sized $\gamma^{\prime} / \gamma^{\prime \prime}$ precipitates effectively hindered the dislocation motion in the grain interior. In addition, controlled grain boundary $\delta$ precipitates inhibited grain boundary sliding and decelerated the steady-state creep strain rate during creep deformation.
\end{abstract}

Keywords: electron beam melting; superalloy; IN718; additive manufacturing; creep

\section{Introduction}

Developed in the early 1960s, the nickel-iron based IN718 alloy features high-temperature strength and outstanding corrosion resistance up to $700^{\circ} \mathrm{C}$. IN718 derives its high-temperature strength from the ordered body-centered tetragonal $\gamma^{\prime \prime}$ phase $\left(\mathrm{Ni}_{3} \mathrm{Nb}, \mathrm{D0}_{22}\right.$, ordered $\left.\mathrm{BCT}\right)$ and face-centered cubic $\gamma^{\prime}$ phase $\left(\mathrm{Ni}_{3}(\mathrm{Al}, \mathrm{Ti}), \mathrm{L1}_{2}\right.$, ordered FCC), which are both coherent to the matrix. For the peak-aged IN718 alloy, the fraction of $\gamma^{\prime \prime}$ reaches 15 vol.\% and thus contributes to the major hardening effect compared to the 4 vol.\% $\gamma^{\prime}$ phase [1]; however, when exposed to a temperature higher than $700{ }^{\circ} \mathrm{C}$, the meta-stable $\gamma^{\prime \prime}$ precipitates tend to transform rapidly into the thermodynamically stable $\delta$ phase $\left(\mathrm{Ni}_{3} \mathrm{Nb}\right.$, orthorhombic). The formation of the $\delta$ phase, which is incoherent to the matrix, lowers the strength of IN718 by depleting the major strengthened $\gamma^{\prime \prime}$ phase, thereby limiting the operating temperature range of IN718 [2]. Nevertheless, the controlled grain boundary $\delta$ phase offers some advantages, such as improved grain stability and resistance to creep deformation [3].

As an age-hardenable alloy, IN718 possesses excellent weldability due to its retarded $\gamma^{\prime \prime}$ precipitation-hardening rate and low cracking susceptibility, thus making IN718 suitable for various additive manufacturing (AM) processes [4,5]. AM is a new advanced manufacturing process that enables the fabrication of components with complex designs, which are problematic in manufacturing using traditional methods. Electron beam melting (EBM) is one of the most popular and widely used metal additive manufacturing techniques for producing high-density metallic parts by melting metal powders in a layer-by-layer manner using a high-power electron beam [6]. Powder preheating in the EBM process relieves the residual stress in the final built parts by lowering the thermal gradient between the layers [7]. The vacuum environment in the built chamber prevents oxidation 
during the EBM process and makes it highly suitable for processing reactive materials such as TiAl-based alloys [8,9]. Considering its benefits, EBM was applied to manufacture high-performance IN718 with complex components for various applications, especially aerospace applications.

In recent years, researchers have tried to optimize the microstructure and the precipitates for EBM-built IN718 by tailoring the post-heat-treatment to meet requirements for various mechanical properties. Strondl et al. reported the tensile properties of an EBM-built IN718 that were comparable to those of the conventionally wrought IN718 alloy [10]. Goel et al. successfully reduced the defects within EBM-built IN718 using a hot isostatic pressing (HIP) process [11]. Nandwana et al. showed the possibility of grain-size control without the help of a phase during the HIP process by closely controlling the building temperature [12]. Deng et al. proposed the direct-aging process, which effectively avoided the formation of the $\delta$ phase, as the optimal heat treatment for EBM-built IN718 and its room-temperature tensile properties [13]. Kirka et al. identified a three-layer structure along the building direction of EBM-built IN718 bulk and declared that the network of needle-like $\delta$ phase formed at the lower level of the bulk weakened the tensile properties [14].

According to the abovementioned literature, the $\delta$ phase plays a dominant role in the tensile properties of EBM-built IN718; however, little emphasis has been placed on elucidating the influence of the $\delta$ phase on the creep properties. In this research, we focus on the creep properties of EBM-fabricated IN718 heat-treated at various conditions. The evolution of the microstructure and its relationship to the creep properties have been elucidated. As the post-heat-treatment that optimizes creep properties has not been published yet, this study aims to provide guidelines for optimizing heat treatment for the EBM-built IN718 alloy.

\section{Materials and Methods}

In this study, we used Arcam Inco718 powders (Arcam AB, Mölndal, Sweden) with the nominal composition given in Table 1. Mostly, these powders are spherical or irregular in shape, with few satellite particles on the surface. A cubic block with dimensions of $45 \times 45 \times 45 \mathrm{~mm}^{3}$ was fabricated using Arcam A2X EBM machine (Arcam AB, Mölndal, Sweden) and sliced into several $3 \mathrm{~mm}$-thick plates using a spark cutter. The sliced plates were heat-treated, following the conditions listed in Table 2 for the creep test and microstructure observation. All the heat treatments were performed in a box furnace (FT-105FM, FULL-TECH, Osaka, Japan). To prevent oxidation, the specimens were sealed in quartz capsules under a vacuum. The dog-bone-shaped specimens for creep tests with a gauge length of $19.6 \mathrm{~mm}$ and a $2.5 \times 3.0 \mathrm{~mm}^{2}$ cross section were cut using a wire electrodischarge machine (WEDM, HS-300, Brother Industries Ltd., Nagoya, Japan) parallel to the building direction (BD). The tensile creep tests were carried out at $650{ }^{\circ} \mathrm{C}$, using an RT-20 constant-load creep testing machine with an attached Bethel-4A automatic temperature control unit (Toshin Kogyo Co., Ltd., Tokyo, Japan) under a stress level of $650 \mathrm{MPa}$. The creep specimens were heated from room temperature to a selected test temperature at a heating rate of $10^{\circ} \mathrm{C} / \mathrm{min}$. After $30 \mathrm{~min}$ of soaking time to obtain a uniform and stable temperature, the tests were performed until fracture, followed by furnace cooling. The temperature fluctuation during the creep test was controlled within $\pm 2{ }^{\circ} \mathrm{C}$ using k-type thermocouples that were in contact with the specimen. The creep strain was measured during tests using a linear variable differential transducer (LVDT) (PEACOCK, Model D-10S, OZAKI MFG. Co. Ltd., Tokyo, Japan) extensometer mounted on the specimen. To characterize the microstructure, the specimens were sequentially ground with SiC emery papers from 240 to 2000 grit and then underwent metallographic polishing with 9 and $3 \mu \mathrm{m}$ diamond suspensions, and finally were polished with colloidal silica suspension. The electrochemical etching was performed using an electrolytic solution of phosphorus acid and water $\left(1: 4\right.$, by volume) at $25^{\circ} \mathrm{C} / 2.5 \mathrm{~V}$ for $3-5 \mathrm{~s}$. The microstructures were analyzed using a scanning electron microscope (SEM, S-3700N, Hitachi Ltd., Tokyo, Japan) with an attached electron backscattered electron (EBSD) detector (HKL Nordlys, Oxford Instrument, 
Abingdon, UK). The EBSD data were further analyzed using HKL-channel 5 software. A field-emission scanning electron microscope (FE-SEM, JSM-7800F Prime, JEOL Ltd., Tokyo, Japan) was used to obtain a high resolution. The nano-sized precipitates and the dislocations were observed using a transmission electron microscope (TEM; JEM-2010HC, JEOL, Tokyo, Japan) operating at an accelerating voltage of $200 \mathrm{kV}$. TEM samples were prepared by grinding to $60-100 \mu \mathrm{m}$ thick through mechanical polishing, and $3 \mathrm{~mm}$ discs were punched out. The discs were then electro-polished using a twin-jet electro-polisher (Model 110, E.A. Fischione Instruments, Inc., Export, PA, USA) with an electrolytic solution consisting of $10 \%$ perchloric acid and $90 \%$ ethanol at $-30{ }^{\circ} \mathrm{C} / 30 \mathrm{~V}$ for $5-7 \mathrm{~min}$.

Table 1. Nominal chemical composition of EBM 718 powders (mass \%).

\begin{tabular}{cccccccccccccc}
\hline IN718 & $\mathbf{N i}$ & $\mathbf{C r}$ & $\mathbf{N b}$ & $\mathbf{M o}$ & $\mathbf{T i}$ & $\mathbf{A l}$ & $\mathbf{C o}$ & $\mathbf{C u}$ & $\mathbf{C}$ & $\mathrm{Si}$ & $\mathbf{M n}$ & $\mathbf{O}$ & Fe \\
\hline EBM & 52.59 & 19.3 & 4.89 & 3.04 & 1.07 & 0.54 & 0.01 & 0.04 & 0.03 & 0.05 & 0.17 & $142 \mathrm{ppm}$ & Bal. \\
\hline C\&W & 53.16 & 18.8 & 5.01 & 2.99 & 0.92 & 0.60 & 0.28 & 0.03 & 0.04 & 0.07 & 0.02 & $7 \mathrm{ppm}$ & Bal. \\
\hline
\end{tabular}

EBM: Electron Beam Melting; C\&W: Cast and Wrought.

Table 2. Details of the heat-treatment conditions for the EBM IN718 and corresponding nomenclature.

\begin{tabular}{ccc}
\hline Specimen & Solutionization/Homogenization & Aging \\
\hline $\mathrm{AB}$ & - & - \\
$\mathrm{DA}$ & - & $720^{\circ} \mathrm{C} / 8 \mathrm{~h} / \mathrm{FC}+620^{\circ} \mathrm{C} / 10 \mathrm{~h} / \mathrm{AC}$ \\
$\mathrm{SA}$ & $980^{\circ} \mathrm{C} / 1 \mathrm{~h} / \mathrm{AC}$ & $720^{\circ} \mathrm{C} / 8 \mathrm{~h} / \mathrm{FC}+620^{\circ} \mathrm{C} / 10 \mathrm{~h} / \mathrm{AC}$ \\
$\mathrm{HSA}$ & $1095^{\circ} \mathrm{C} / 1 \mathrm{~h} / \mathrm{AC}+955^{\circ} \mathrm{C} / 6 \mathrm{~h} / \mathrm{AC}$ & $720^{\circ} \mathrm{C} / 8 \mathrm{~h} / \mathrm{FC}+620^{\circ} \mathrm{C} / 10 \mathrm{~h} / \mathrm{AC}$ \\
$\mathrm{HA}$ & $1095^{\circ} \mathrm{C} / 1 \mathrm{~h} / \mathrm{AC}$ & $720^{\circ} \mathrm{C} / 8 \mathrm{~h} / \mathrm{FC}+620^{\circ} \mathrm{C} / 10 \mathrm{~h} / \mathrm{AC}$ \\
$\mathrm{C} \& W$ & $980^{\circ} \mathrm{C} / 1 \mathrm{~h} / \mathrm{AC}$ & $720^{\circ} \mathrm{C} / 8 \mathrm{~h} / \mathrm{FC}+620^{\circ} \mathrm{C} / 10 \mathrm{~h} / \mathrm{AC}$ \\
\hline
\end{tabular}

Nomenclature: AB: as-built, DA: direct-aged, SA: solutionized and aged, HSA: homogenized + solutionized and aged, HA: homogenized and aged, C\&W: cast and wrought, FC: furnace-cooled, AC: air-cooled.

\section{Results}

\subsection{Microstructural Features}

The EBSD inverse pole figure (IPF) map of the as-built specimen along the building direction given in Figure 1 revealed high-aspect-ratio columnar grains with strong $<100>$ crystallographic orientation along the building direction of the EBM process. However, occasionally a few fine equiaxed grains of random crystallographic orientation were also observed. The equiaxed grains formed due to solidification conditions such as the thermal gradient and growth rate, both of which favor the formation of new fine grains [15]. Another possible reason could be the presence of nano-sized Al-rich oxide particles or the dendritic fragments caused by the highly focused beam, which introduces new equiaxed grains of random crystallographic orientations [16].

The EPMA elemental maps for the as-built specimen are shown in Figure 2, revealing the presence of spherical black Al-rich oxides $\left(\mathrm{Al}_{2} \mathrm{O}_{3}\right)$ and TiN. The impurity contamination very likely came from the powder feedstock, which is more vulnerable to contamination. The $\mathrm{Al}_{2} \mathrm{O}_{3}$ particles were found to be typically less than $1 \mu \mathrm{m}$. The STEM-EDS analysis in Figure 3 shows the "core-shell" structure of aluminum oxide $\left(\mathrm{Al}_{2} \mathrm{O}_{3}\right)$ at the center and surrounded by carbo-nitrides. This core-shell structure formation suggests that carbonitrides typically nucleate and grow at the $\mathrm{Al}_{2} \mathrm{O}_{3}$ interface during solidification. 


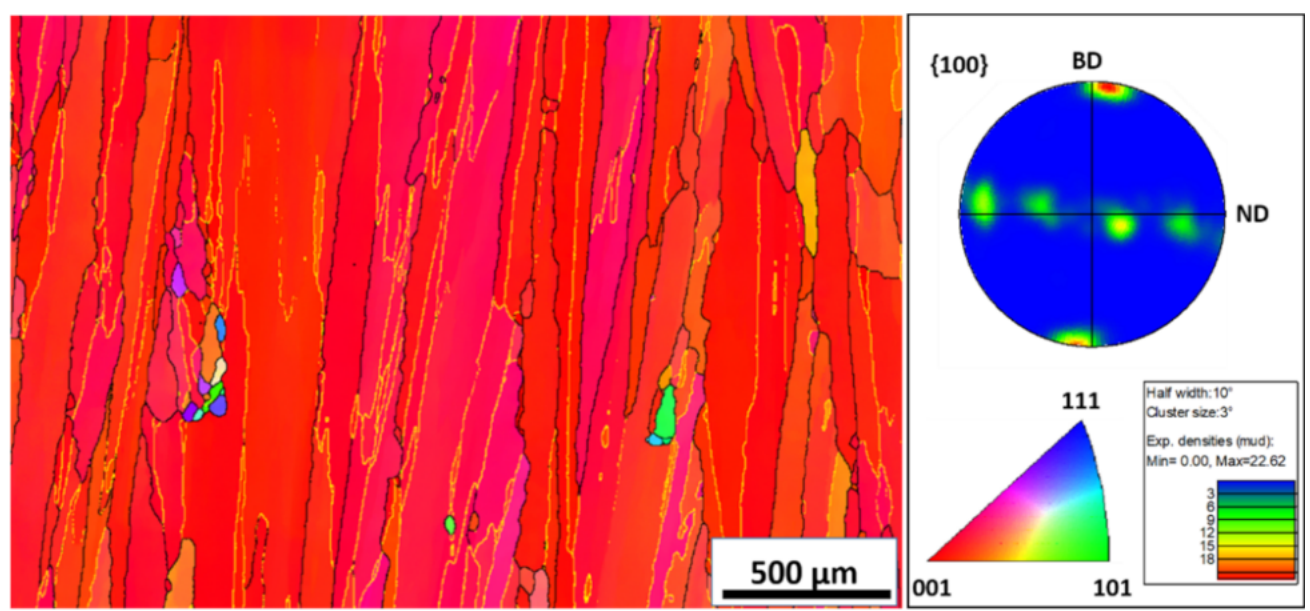

Figure 1. EBSD-IPF map of as-built EBM IN718 specimen with $<001>$ orientation to the building direction. In the map, the low-angle grain boundaries (LABs) $\left(2^{\circ} \leq \theta<10^{\circ}\right)$ and high-angle grain boundaries (HABs) $\left(10^{\circ} \leq \theta\right)$ are indicated by yellow and black lines, respectively. (BD: Building Direction, ND: Normal Direction).

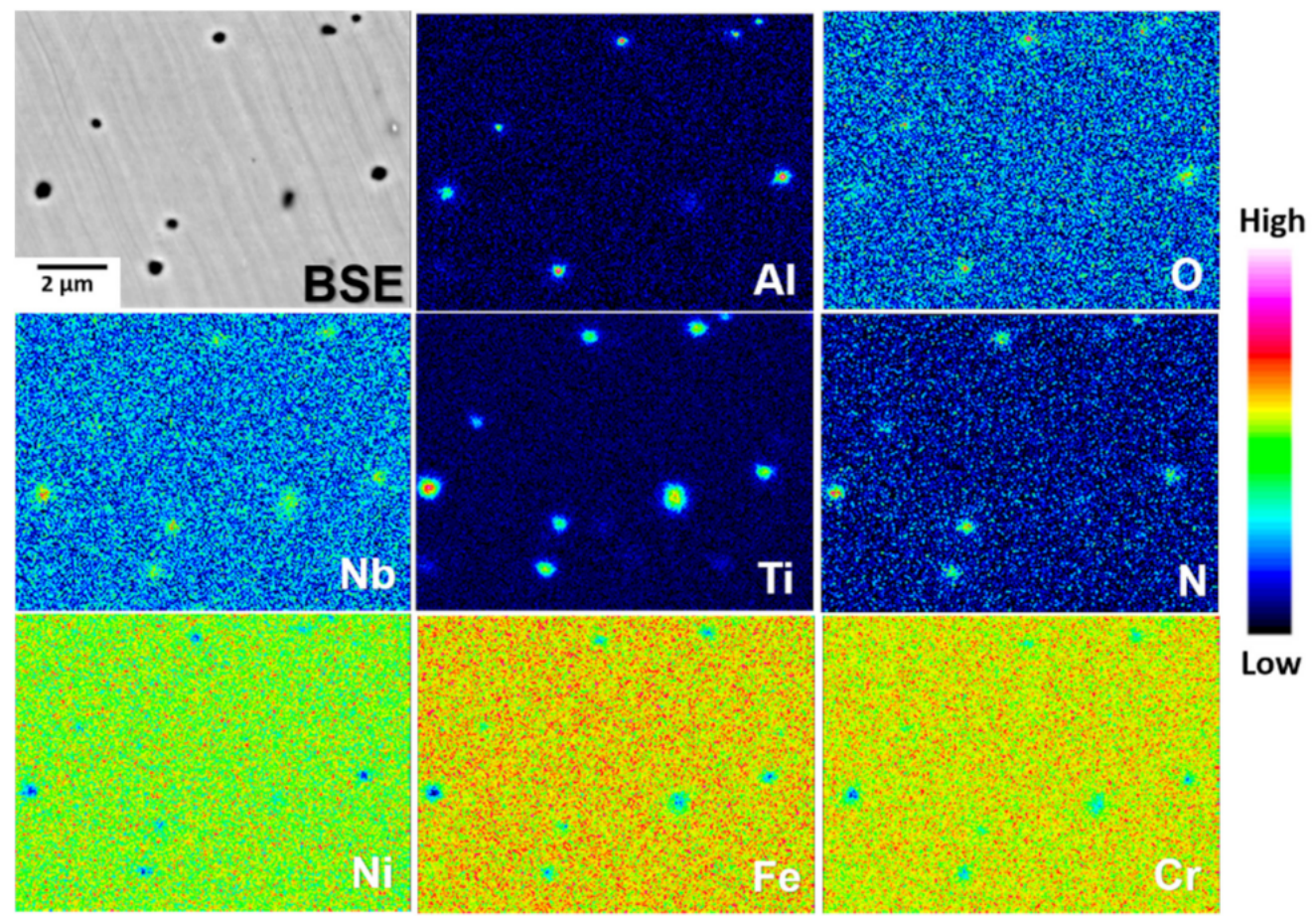

Figure 2. EPMA element maps showing the formation of $\mathrm{Al}_{2} \mathrm{O}_{3}$ and TiN in the EBM IN718 as-built specimen along the building direction [17] (BSE: Backscattered Electrons image).

As shown in Figure 4a, the SEM micrographs of the AB specimen reveal an array of MC carbides $(\mathrm{M}=\mathrm{Nb}, \mathrm{Ti})$, precipitated both on the grain boundaries and in the grain interior. These carbides were mostly aligned parallel to the building direction. The magnified view in Figure $4 \mathrm{~b}$ shows very fine precipitates throughout the matrix, as well as fine-sized $\delta$ precipitates formed along the grain boundary with the precipitation-free zone (PFZ). These fine precipitates can be identified as $\gamma^{\prime} / \gamma^{\prime \prime}$ phases using TEM bright-field (BF) and dark-field (DF) images coupled with their corresponding selected-area diffractions (SAD), as shown in the insert of Figure 5. 

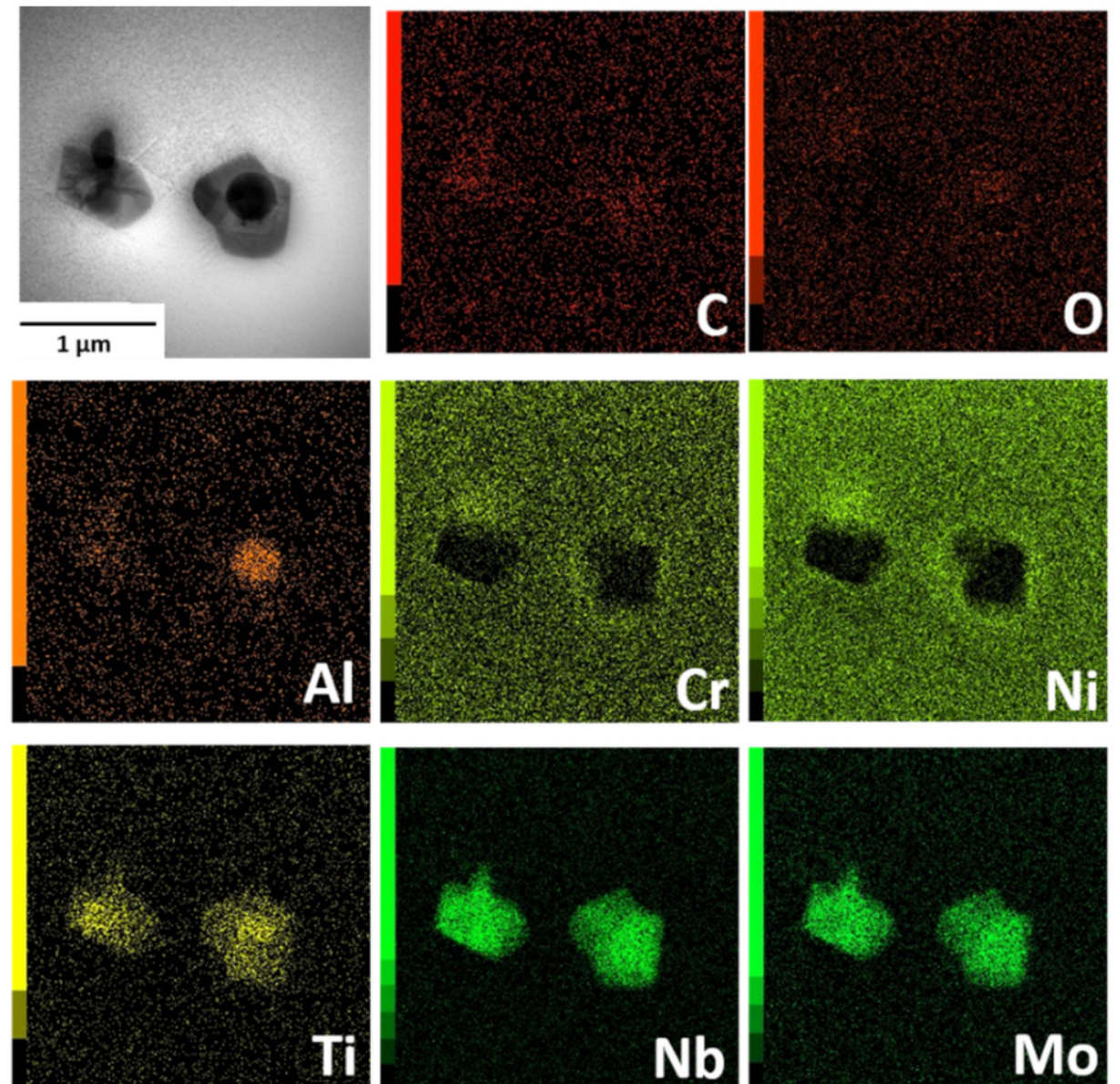

Figure 3. STEM image showing "core-shell" structures of $\mathrm{Al}_{2} \mathrm{O}_{3}$ and $(\mathrm{Ti}, \mathrm{Nb}) \mathrm{C}$ and the corresponding WDS elemental maps of $\mathrm{C}, \mathrm{O}, \mathrm{Al}, \mathrm{Cr}, \mathrm{Ni}, \mathrm{Ti}, \mathrm{Nb}$, and Mo of the as-built EBM IN718.
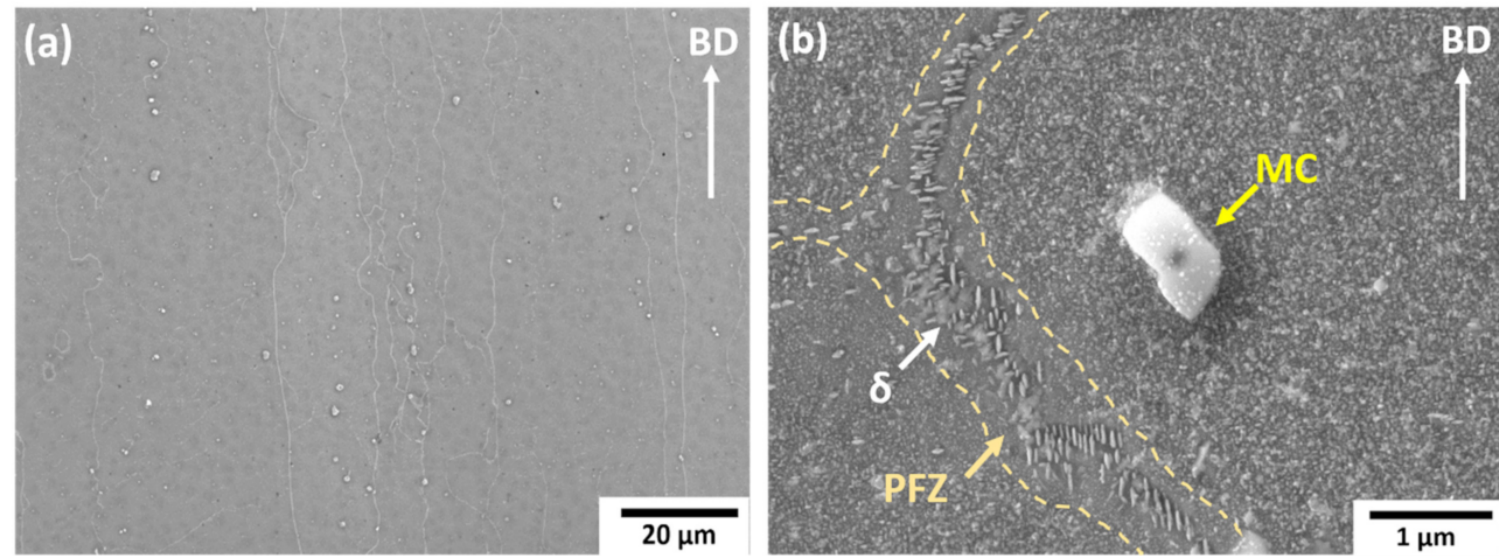

Figure 4. SEM micrographs showing grain morphology and precipitation along the grain boundary in as-built EBM IN718 parallel to the building direction, (a) at lower magnification and (b) at higher magnification. (BD: Building Direction, PFZ: Precipitate Free Zone). 


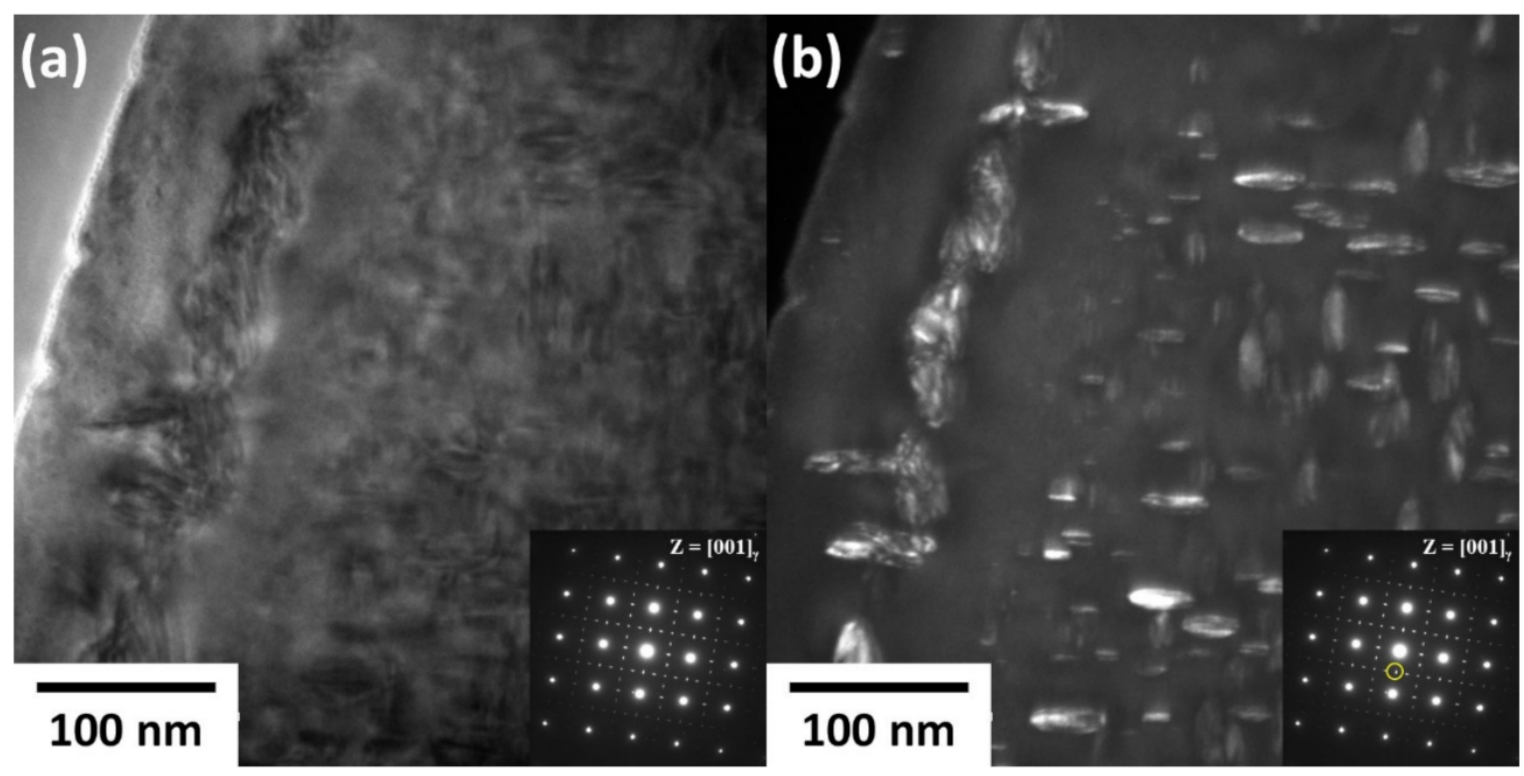

Figure 5. TEM images of as-built specimen were taken from the [001] zone axis, showing nano-scale $\gamma^{\prime} / \gamma^{\prime \prime}$ precipitates-(a) bright-field image, (b) dark-field image.

Figure 6 shows the EBSD inverse pole figure (IPF) map of the post-heat-treated specimens. After the post-heat treatments, the microstructure appeared to be unaffected in terms of grain morphology, as it still maintained a columnar-grained structure with a preferential $<100>$ crystallographic orientation. In general, columnar grains are considered to be beneficial for enhancing the creep properties of Ni-based superalloys, especially with $<100>$ or $<111>$ orientations [18-22]. Because of the high thermal stability of $\mathrm{Al}_{2} \mathrm{O}_{3}$ and TiN and the high dissolution temperature of MC carbide (approximately $1250^{\circ} \mathrm{C}$ [23]), these phases remained intact after the heat treatments. The microstructure of the DA specimen is shown in Figure $7 \mathrm{a}, \mathrm{b}$. The grain boundary $\delta$ precipitates became slightly longer than their counterparts in the $\mathrm{AB}$ specimen. Assisted by the two-step aging post-treatment, the size of the strengthening $\gamma^{\prime} / \gamma^{\prime \prime}$ phases also increased, as shown in Figure 7b. For the SA specimen, both the $\gamma^{\prime \prime}$ and $\gamma^{\prime}$ phases within the matrix were expected to dissolve at the $980^{\circ} \mathrm{C} / 1 \mathrm{~h}$ stage, whereas a high fraction of $\delta$ phase forms along the grain boundaries. However, in the case of the HSA specimen, not only were the $\gamma^{\prime} / \gamma^{\prime \prime}$ phases dissolved, but the $\delta$ phase was also dissolved at $1095^{\circ} \mathrm{C} / 1 \mathrm{~h}$, and the grain boundary was kept clean up to the stage of $955{ }^{\circ} \mathrm{C} / 6 \mathrm{~h}$, during which the $\delta$ phase formed rapidly. According to previous research, the maximum intergranular $\delta$ phase precipitation is found in the $900{ }^{\circ} \mathrm{C}-980^{\circ} \mathrm{C}$ temperature range due to higher diffusional rates and accelerated nucleation at grain boundaries [23,24]. Therefore, the grain boundary $\delta$ precipitates grew larger and their shape changed from a fine disc to a thick needle shape in both the SA and HSA specimens shown in Figure 7c,e, respectively. These specimens underwent strengthening through the following two-step aging heat treatment. However, strengthening $\gamma^{\prime} / \gamma^{\prime \prime}$ phases in SA and HSA specimens, as presented in Figure $7 \mathrm{~d}, \mathrm{f}$, became fine in size compared to the DA specimen. The only difference between HSA and HA is the $955{ }^{\circ} \mathrm{C} / 6 \mathrm{~h}$ secondary solution treatment step, which is performed to achieve a higher volume fraction of acicular $\delta$ precipitates along the grain boundary. Thus, the SEM micrographs of the HA specimen in Figure $7 \mathrm{~g}$ show the grain boundaries that are free of $\delta$ precipitates and fine $\gamma^{\prime} / \gamma^{\prime \prime}$ phases in the grain interior, as shown in Figure 7h. 

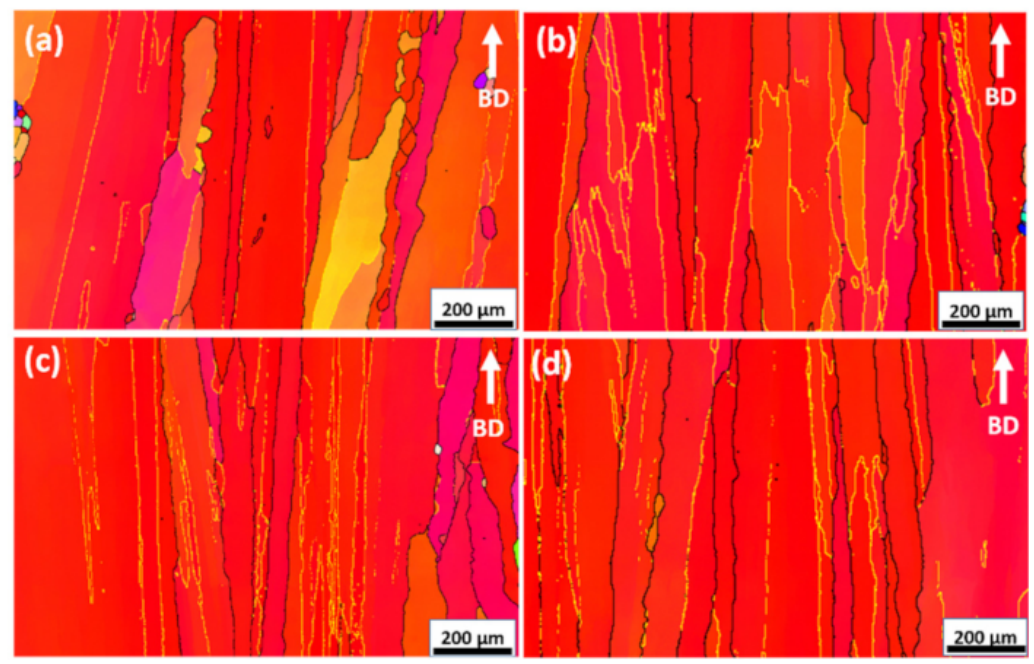

Figure 6. EBSD-IPF maps of post-heat-treated specimens along the building direction: (a) DA, (b) STA, (c) HSA, (d) HA. The low-angle grain boundaries (LABs) $\left(2^{\circ} \leq \theta<10^{\circ}\right)$ and high-angle grain boundaries (HABs) $\left(10^{\circ} \leq \theta\right)$ are indicated by yellow and black lines, respectively.

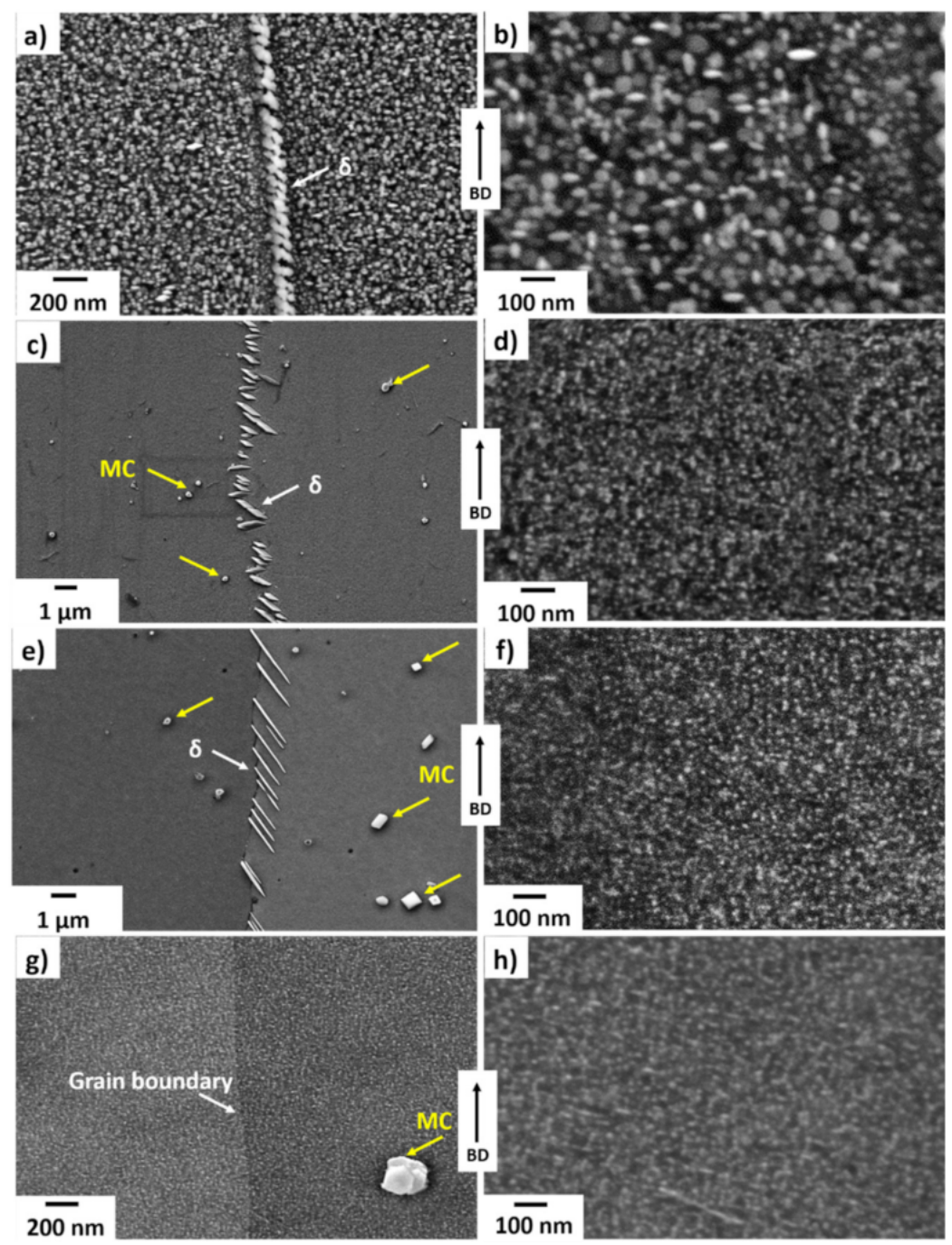

Figure 7. SEM micrographs showing grain boundary $\delta$ phase morphology and $\gamma^{\prime} / \gamma^{\prime \prime}$ precipitates for various heat treatments: (a,b) DA, (c,d) SA, (e,f) HSA, (g,h) HA. The black arrows indicate the building direction. 


\subsection{Creep Properties}

Figure 8 presents the creep curves of various heat treatment specimens along the building directions, tested at $650{ }^{\circ} \mathrm{C} / 650 \mathrm{MPa}$. For comparison, the $\mathrm{C} \& W \mathrm{IN718}$ creep curve is also included. The corresponding creep properties, such as creep life, elongation, and creep strain rates, are summarized in Table 3 . The creep rupture life of the AB specimen was approximately $296 \mathrm{~h}$. The DA specimen showed a rupture life of $617 \mathrm{~h}$, which is twice that of the $\mathrm{AB}$ specimen. Both $\mathrm{AB}$ and DA specimens displayed conventional creep curves with a short primary creep regime and a longer steady-state regime, followed by an accelerated tertiary regime. In contrast, both the SA and HSA specimens showed early tertiary regimes with shorter creep rupture lives of $124 \mathrm{~h}$ and $116 \mathrm{~h}$, respectively. The HA specimen exhibited a creep life of $239 \mathrm{~h}$ with an elongation of $9.66 \%$. By comparison, the creep life of HA was shorter than those of the AB and DA specimens, which had fine $\delta$ precipitates along their grain boundaries. However, the elongation of the HA specimen was roughly 2.5 times higher than those of $\mathrm{AB}$ and $\mathrm{DA}$. The DA specimen had the lowest steady-state creep rate, as low as $0.15 \times 10^{-8} \mathrm{~s}^{-1}$. The creep rates of the $\mathrm{AB}$ and $\mathrm{SA}$ specimens were $0.50 \times 10^{-8} \mathrm{~s}^{-1}$ and $5.0 \times 10^{-8} \mathrm{~s}^{-1}$, respectively. The creep rate of the HT specimen reached $5.5 \times 10^{-8} \mathrm{~s}^{-1}$. The HA specimen showed a creep rate of $1.0 \times 10^{-8} \mathrm{~s}^{-1}$.
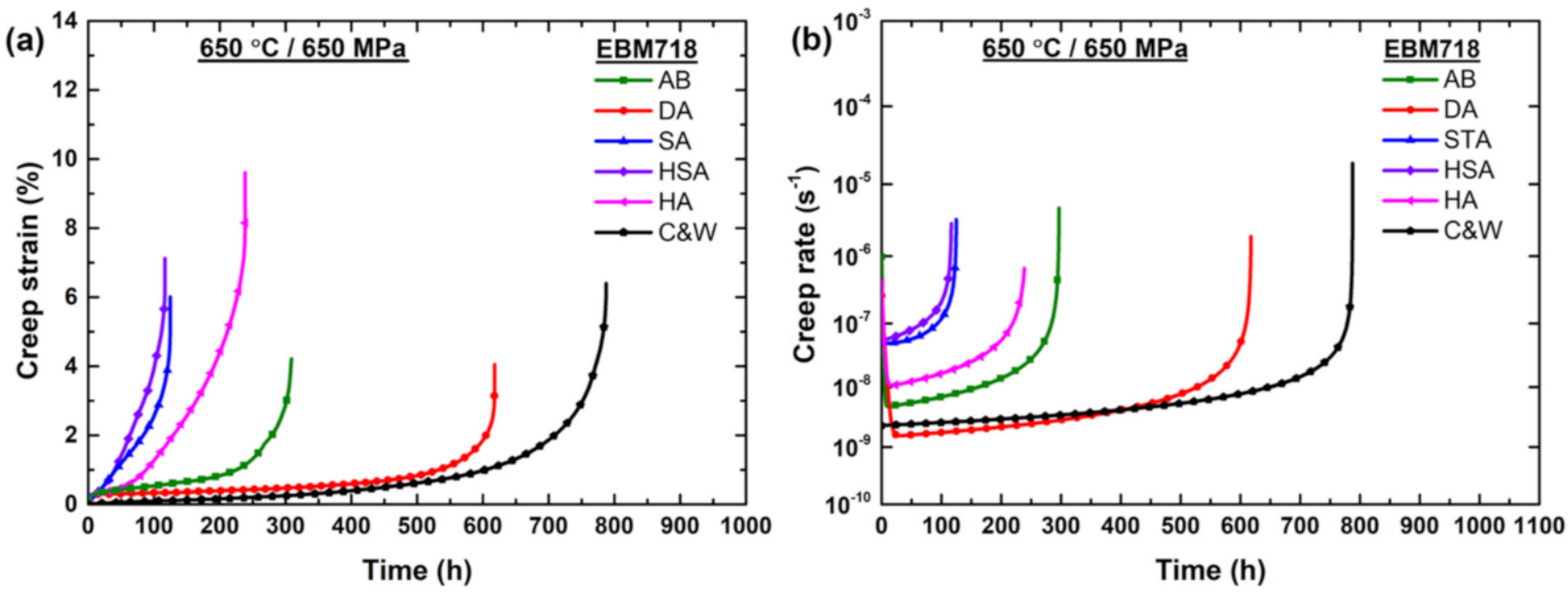

Figure 8. Plots showing creep properties of EBM IN718 for as-built and various post-heat-treated specimens along the building direction; (a) depicts the creep curves at $650{ }^{\circ} \mathrm{C}$ and $650 \mathrm{MPa}$, and (b) shows the correlations between creep rate and time.

Table 3. The creep properties of as-built and various post-heat-treated specimens presented in Figure 8.

\begin{tabular}{cccc}
\hline Specimen & Creep Life (h) & Creep Elongation (\%) & Minimum Creep Rate (10 $\mathbf{1 0}^{-\mathbf{8}} \mathbf{s}^{-\mathbf{1})}$ \\
\hline AB & 296.78 & 4.20 & 0.50 \\
DA & 617.05 & 4.05 & 0.15 \\
SA & 124.70 & 6.05 & 4.96 \\
HSA & 116.46 & 7.16 & 5.52 \\
HA & 238.62 & 9.64 & 1.01 \\
C\&W & 787.46 & 6.40 & 0.23 \\
\hline
\end{tabular}

\section{Discussion}

\subsection{Effect of the Post-Heat Treatments on Microstructure Evolution}

Microstructural aspects, such as the chemical composition, chemical distribution, morphology, precipitate size, and volume fraction of precipitates, are predominantly controlled via the processing conditions and subsequent post-heat treatments. In our current work, the powder bed was preheated to $800{ }^{\circ} \mathrm{C}$ and was maintained at that temperature throughout the EBM process. After the completion of the build, the block was allowed to 
cool. For the IN718 alloy, the precipitation of $\gamma^{\prime} / \gamma^{\prime \prime}$-strengthening phases occurs in the temperature range of $650{ }^{\circ} \mathrm{C}-900^{\circ} \mathrm{C}$, and the formation of the thermodynamically stable $\delta$ phase takes place in the temperature range of $750{ }^{\circ} \mathrm{C}-1020{ }^{\circ} \mathrm{C}$. As a result, the preheating and cooling processes act together as an in situ heat treatment, promoting the precipitation of $\gamma^{\prime} / \gamma^{\prime \prime}$-strengthening phases and fine $\delta$ precipitates along the grain boundary, with a clear $\gamma^{\prime \prime}$-depleted region in the AB specimen. However, the EBM processing conditions are sufficient to precipitate a relatively high amount of $\gamma^{\prime} / \gamma^{\prime \prime}$ but not enough to obtain peakaging. During two-step direct aging, the size and volume fraction of $\gamma^{\prime} / \gamma^{\prime \prime}$ precipitates in the $\mathrm{AB}$ specimen increased, as the temperature conditions favored the peak aging of these precipitates. In addition, the grain boundary $\delta$ phase also tends to grow larger as it accelerates the transformation of the $\gamma^{\prime \prime}$ phase into the $\delta$ phase. For SA and HSA specimens, the dissolution of $\gamma^{\prime} / \gamma^{\prime \prime}$ and $\delta$ precipitates (the solvus temperatures of $\gamma^{\prime} / \gamma^{\prime \prime}$ and $\delta$ are around $900{ }^{\circ} \mathrm{C}$ and $1020^{\circ} \mathrm{C}$, respectively [23]) into the $\gamma$ matrix results in homogenization of the chemical composition. Additionally, the grain boundaries serve as preferred nucleation sites for the needle-like $\delta$ precipitation [24]. As a result, the homogenized composition and preferential nucleation lead to thicker $\delta$ precipitates at the grain boundary. Since both $\delta$ and $\gamma^{\prime \prime}$ phases have the same chemical composition $\left(\mathrm{Ni}_{3} \mathrm{Nb}\right)$, the precipitation of the coarser $\delta$ phase along the grain boundary consumes the available $\mathrm{Nb}$ content along the vicinity of the grain boundary and reduces the volume fraction of the major strengthening $\gamma^{\prime \prime}$ phase precipitation within the grain during the subsequent two-step aging process. Owing to both the homogenized chemical composition and the modified heat treatment that prevents $\delta$ precipitate formation, the HA specimen obtains a higher volume fraction of $\gamma^{\prime} / \gamma^{\prime \prime}$ precipitates than SA and HSA specimens.

\subsection{Effect of Precipitates on Creep Properties}

Based on the results of a study by Han and Chaturvedi, for alloy IN718 tested at $650{ }^{\circ} \mathrm{C} / 650 \mathrm{MPa}$, the predominant creep mechanism should be the dislocation power-law creep mechanism [25]. The steady-state creep rate equation can be written as

$$
\varepsilon_{s S}^{\circ}=A\left(\frac{\sigma_{a}-\sigma_{0}}{G}\right)^{n_{e}} \frac{G b}{k T} \exp \left(-\frac{Q_{e}}{R T}\right)
$$

where $\varepsilon_{S S}^{\circ}$ is the steady-state creep rate, $A$ is a constant, $\sigma_{a}$ is the applied stress, $\sigma_{0}$ is the threshold stress opposing the dislocation motion, $n_{e}$ is the effective stress exponent, $b$ is the Burgers vector, $Q_{e}$ is the effective activation energy, $T$ is the creep temperature, and $R$ is the gas constant. Moreover, the steady-state creep rate can also be expressed as

$$
\varepsilon_{s s}^{\circ}=\varepsilon_{g}^{\circ}+\varepsilon_{g d s}^{\circ}+\varepsilon_{d i}^{\circ}
$$

where $\varepsilon_{g}^{\circ}$ and $\varepsilon_{g d s}^{\circ}$ represent the contribution of the dislocation process occurring within the grains and the contribution of the grain boundary sliding, respectively. $\varepsilon_{d i}^{\circ}$ represents the stress-directed vacancy diffusion through the lattice and the grain boundary [26]. In this study, the steady-state strain rate $\left(\varepsilon_{s s}^{\circ}\right)$ is primarily controlled by the dislocation motion within the grains, as well as by the grain boundary sliding. In other words, the $\varepsilon_{s S}^{\circ}$ depends mainly on the volume fraction and the size of the primary strengthening $\gamma^{\prime} / \gamma^{\prime \prime}$ and $\delta$ phases obtained during various heat treatment conditions.

In IN718, the growth rate of $\gamma^{\prime} / \gamma^{\prime \prime}$ precipitates follows the Lifshitz-Slyozov-Wagner (LSW) theory of diffusion-controlled growth $[27,28]$. According to LSW theory, the average particle size $(d)$ is proportional to the cube root of aging time $(t)$, i.e., $d \propto t^{1 / 3}$. During the EBM process, the in situ heat treatment forms a relatively coarse $\gamma^{\prime} / \gamma^{\prime \prime}$ precipitation in the $\mathrm{AB}$ specimen. In subsequent direct-aging heat treatment, these pre-existing $\gamma^{\prime} / \gamma^{\prime \prime}$ precipitates coarsen further, owing to the longer aging time. On the other hand, following solutionization/homogenization heat treatment, the relatively coarse pre-existing $\gamma^{\prime} / \gamma^{\prime \prime}$ precipitates dissolve and re-precipitate into a fine size during the aging heat treatment for 
the STA, HSA, and HA specimens. The post-deformed TEM micrographs are shown in Figure 9, demonstrating the formation of stacking faults and micro-twins, which are characteristic features of the dislocation shear mode of deformation. In shearing deformation, the dependence of the steady-state creep rate $\left(\varepsilon_{s s}^{\circ}\right)$ on the average particle size $(d)$ of $\gamma^{\prime \prime}$ precipitates can be expressed as $\varepsilon_{s S}^{\circ} \propto d^{-2}$ [29]. Thus, it is considered that the resistance to creep deformation is higher in the DA specimen with a larger particle size $(40 \mathrm{~nm})$ of $\gamma^{\prime} / \gamma^{\prime \prime}$ precipitates, resulting in the lowest creep rate and longest creep life, as shown in Figure 10.
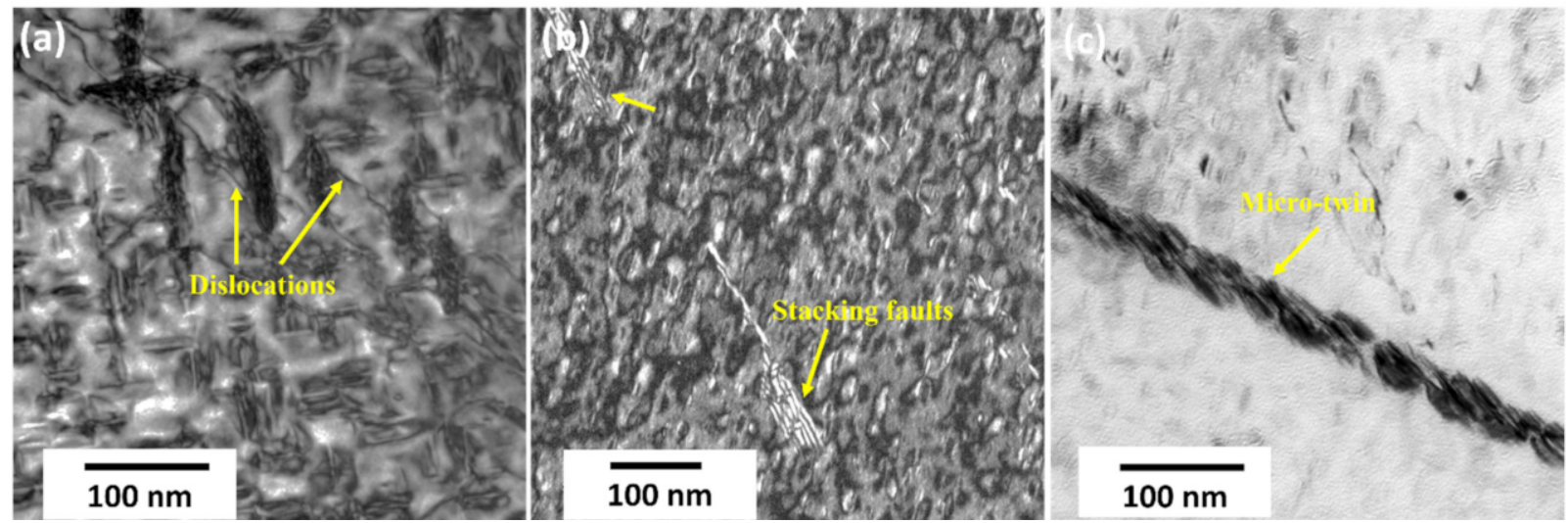

Figure 9. (a) TEM micrographs showing shearing of coarse $\gamma^{\prime \prime}$ precipitates by dislocations after the creep test of $A B$ specimen and $(b, c)$ the formation of stacking faults and micro-twins after the creep test for the DA specimen.

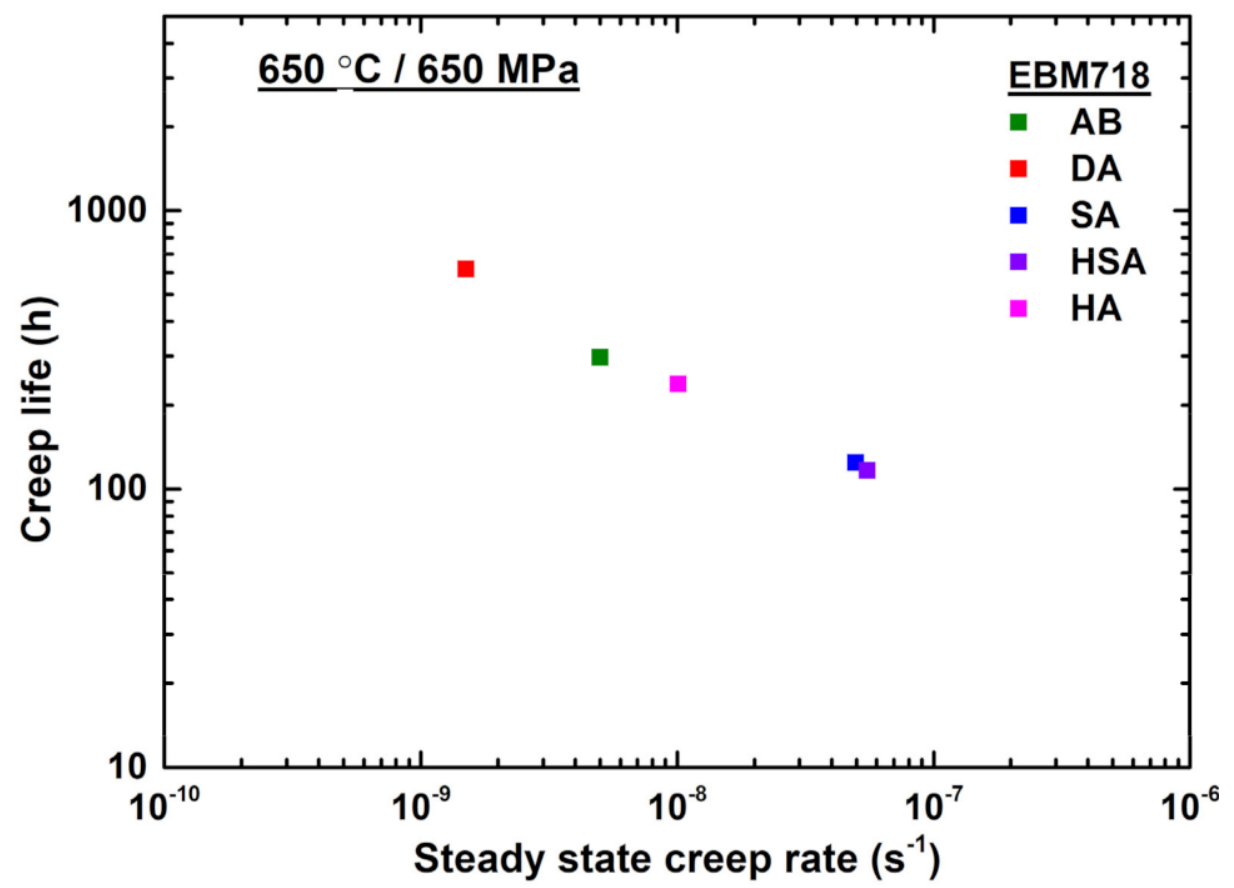

Figure 10. Relationship between creep life and steady rate creep rate for various heat treated specimens.

According to previous studies, it is clear that the grain boundary microstructure strongly influences the creep behavior of IN718 [30,31]. It has been reported that the existence of $\delta$ precipitates at the grain boundary alters the creep deformation mechanism [30]. The size and density of grain boundary $\delta$ precipitates influence the creep fracture behavior of wrought IN718 [31]. The configurations of the precipitates at the grain boundaries differed among the five specimens (Figure 7). Tiny disc-shaped $\delta$ precipitates uniformly decorated the grain boundaries of both $\mathrm{AB}$ and $\mathrm{DA}$ specimens. These tiny precipitates 
effectively hindered the sliding of the grain boundary during creep deformation. However, the DA specimen showed higher creep life with a lower creep strain rate than the $\mathrm{AB}$ specimen, attributable to the former's higher size and volume fraction of $\gamma^{\prime} / \gamma^{\prime \prime}$ precipitates. The $\delta$ phase grew into a needle shape when formed in the temperature range of $815^{\circ} \mathrm{C}-980^{\circ} \mathrm{C}$ [24]. The SA and HSA heat treatments favor the precipitation of the coarse needle-shaped $\delta$ phase along the grain boundary. In general, the needle-shaped $\delta$ phase is incoherent with the $\gamma$ matrix, and its formation is known to lower the amount of strengthening $\gamma^{\prime \prime}$ precipitates, making it undesirable in the IN718 alloy. As the forming $\delta$ precipitates absorb the $\gamma^{\prime \prime}$-forming elements, the $\gamma^{\prime \prime}$-depleted region around the grain boundary increases and eventually weakens the grain boundary in the SA and HSA specimens. The presence of needle-shaped $\delta$ precipitates acts as a preferential nucleation site for creep void formation and damage accumulation, and contributes to the poor creep life compared with the DA specimen.

In addition, the $\mathrm{AB}$ and $\mathrm{DA}$ specimens each have a higher linear density of grain boundary $\delta$ precipitates, at $73 \%$ and $72 \%$, respectively. On the other hand, the linear densities are $38 \%$ and $47 \%$ for the SA and HSA specimens. The increase in the linear density of fine precipitates at the grain boundary reduces the shear stress shared by individual $\delta$ precipitates and delays void formation. This is evident from the creep rate vs. creep time curve shown in Figure 8b, which shows a longer creep time for the onset of the tertiary creep in the AB and DA specimens. In contrast, for the STA and HSA specimens with a low linear density of acicular $\delta$ precipitates, the creep void forms rapidly and results in accelerated tertiary creep. The embrittlement of the $\delta$ phase can be seen from the postcreep microstructure of the SA and HSA specimens shown in Figure 11. The creep voids form at the acicular $\delta$ phase along the grain boundary and link up to develop unstable microcracks. These unstable microcracks finally result in intergranular fractures, thus reducing the creep life. The HA specimens were free of $\delta$ precipitates at the grain boundary and showed higher elongation due to grain boundary sliding. According to Kuo et al., for the forged polycrystalline alloy IN718 with clean grain boundaries, the mechanism underlying grain boundary sliding was activated during the creep test at $650{ }^{\circ} \mathrm{C} / 625 \mathrm{MPa}$ and resulted in the highest strain, up to $5.6 \%$ [32]. The post-creep microstructure of the HA specimen is presented in Figure $11 \mathrm{~g}$, and $\mathrm{h}$ shows wedge-type cracks at the triple points. The disappearance of the grain boundary $\delta$ phase makes the grain boundary sliding easier in the HA specimen. During grain boundary sliding, stress piles up at the triple points and forms cracks, leading to fracture. It can also be noted that some voids appear to form at the grain boundary carbides. However, the distributions of carbides at the grain boundary are similar for all specimens, and the triple points are the site with the greatest potential for damage initiation; it is believed that the carbides play a minor role in the final fracture. 

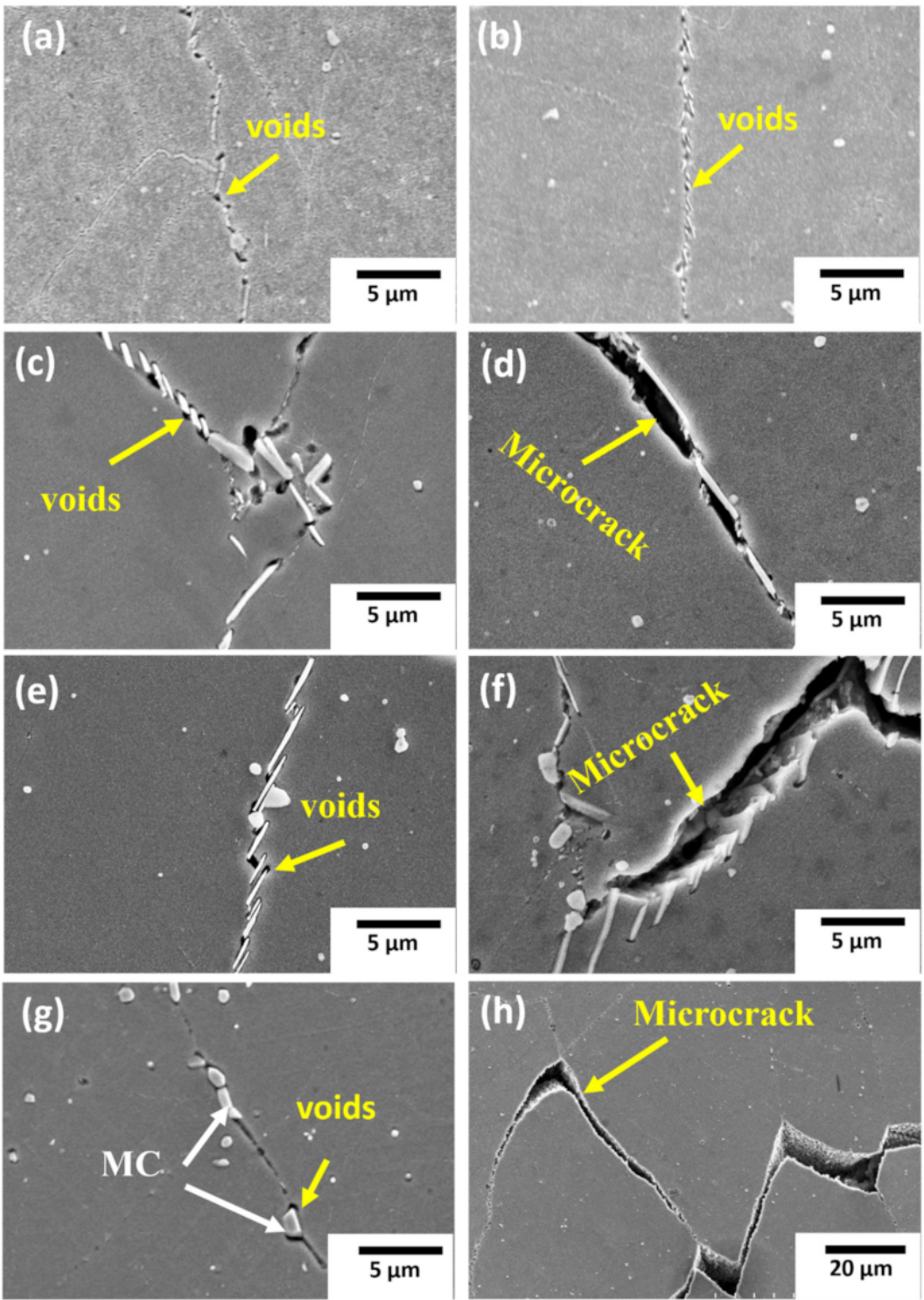

Figure 11. SEM micrographs of cross-sections of crept specimens showing voids and microcracks at grain boundary $\delta$ precipitates of $(\mathbf{a}) \mathrm{AB},(\mathbf{b}) \mathrm{DA},(\mathbf{c}, \mathbf{d}) \mathrm{SA}$, and $(\mathbf{e}, \mathbf{f}) \mathrm{HSA}$, and at grain boundary carbides of $(\mathbf{g}, \mathbf{h})$ HA.

\subsection{Creep Properties in Comparison with Cast and Wrought IN718}

The microstructure of cast and wrought (C\&W) IN718 is shown in Figure 12; the EBSD map reveals very fine equiaxed grains with random orientations. The average grain size was measured to be $\sim 22 \mu \mathrm{m}$. The fracture surfaces and post-deformation microstructures of C\&W and EBM IN718-STA are given in Figures 13 and 14. The cracks originated at the fine grains of EBM IN718, and the local misorientation map showed that dislocations piled up at fine grains, in contrast to the C\&W IN718, in which the deformation was uniform. These findings suggest that incompatible deformation occurs in EBM IN718 during creep deformation, resulting in crack formation. These cracks decrease the actual load-carrying area and speed up the final fracture. The C\&W IN718, on the other hand, exhibited uniform deformation due to homogeneous grains. 


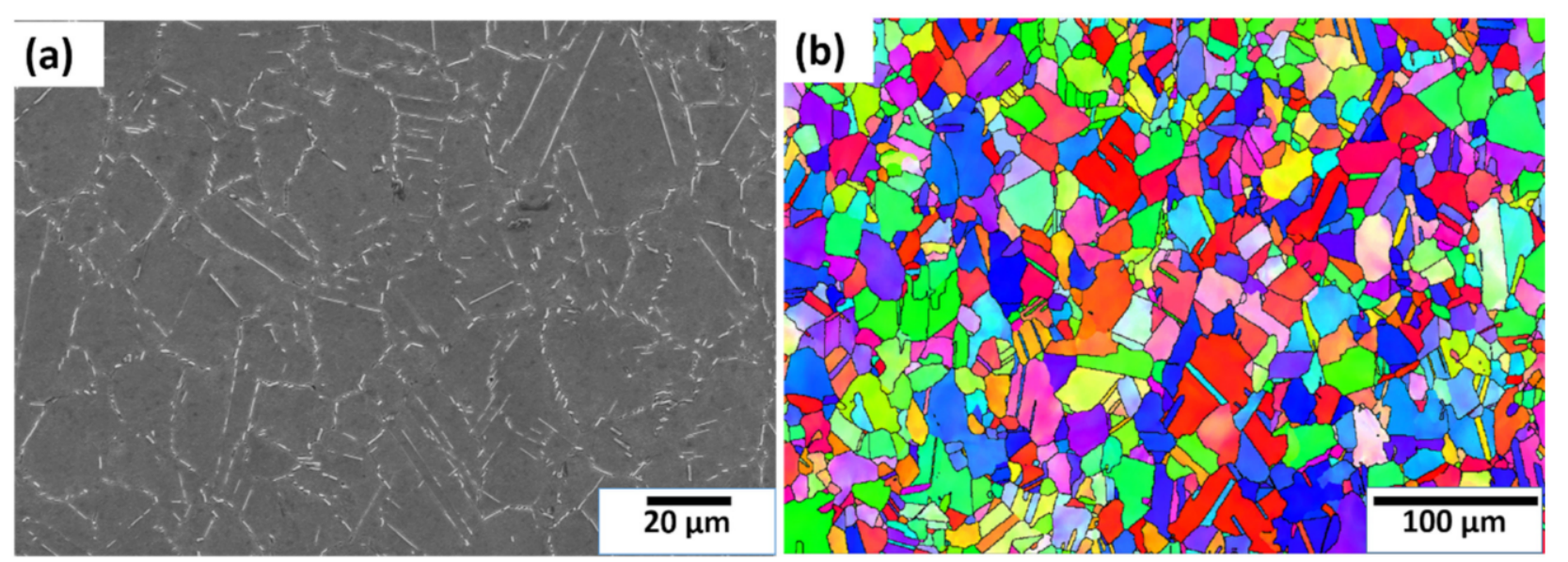

Figure 12. (a) SEM micrograph of C\&W IN718 showing precipitates and (b) EBSD orientation map showing random orientation.
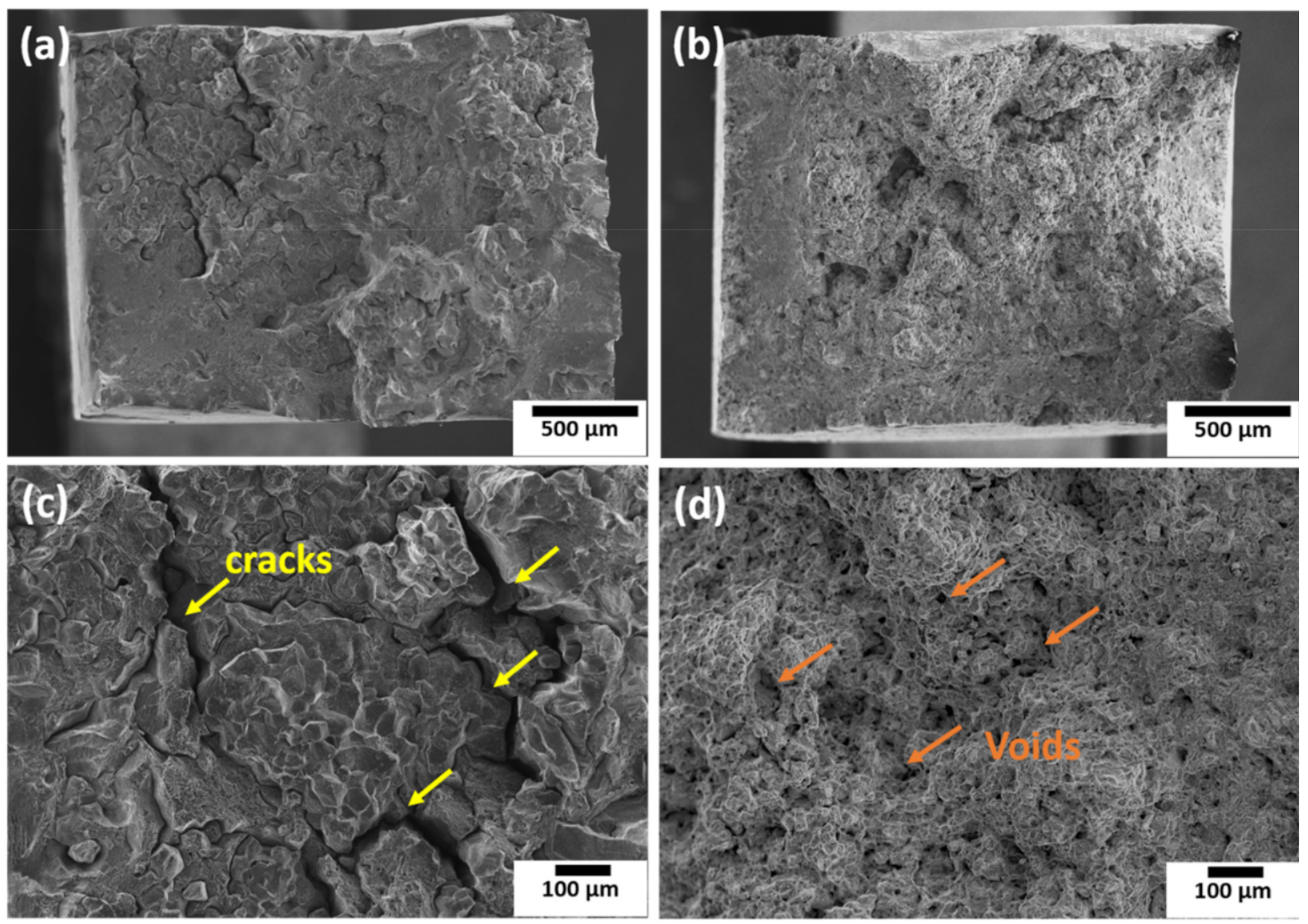

Figure 13. SEM micrographs showing fracture surface morphologies of specimens after the creep test for $(\mathbf{a}, \mathbf{c})$ the EBM IN718 STA specimen and $(\mathbf{b}, \mathbf{d})$ the C\&W IN718 specimen. 


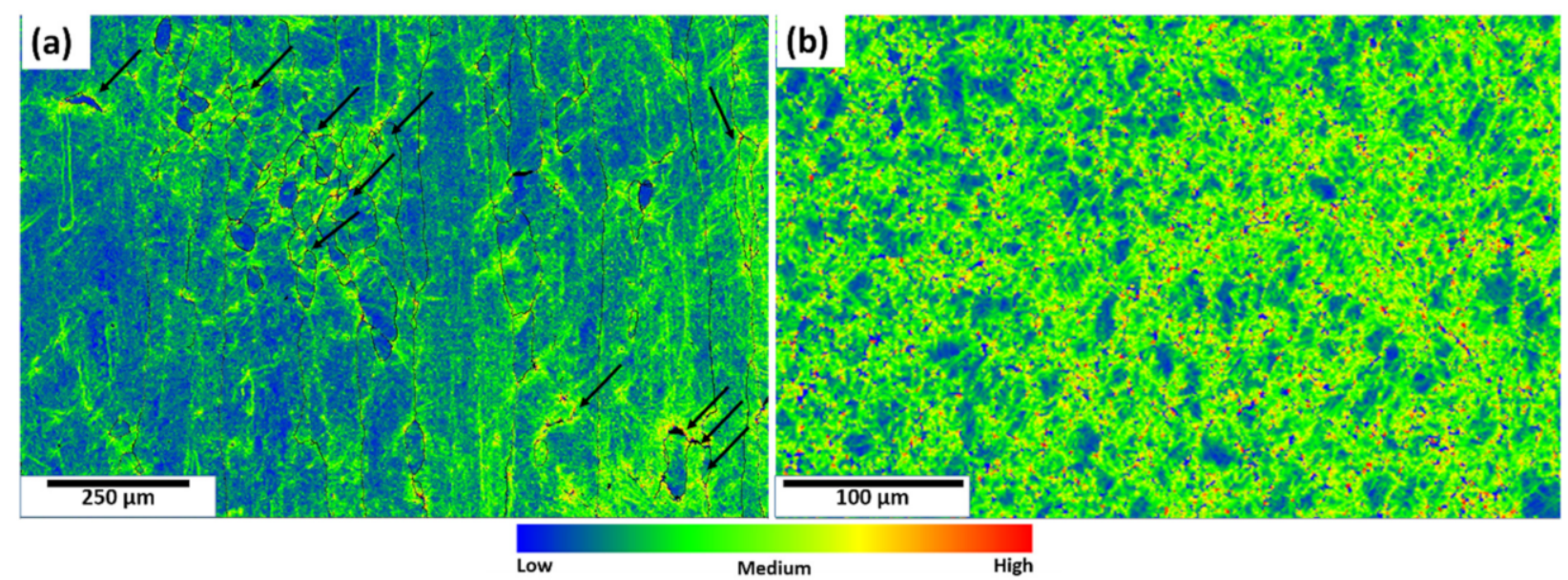

Figure 14. Local misorientation maps after creep test for (a) the EBM IN718 specimen and (b) the C\&W IN718 specimen. The black arrows indicate fine grains.

Moreover, the EBM process uses metal powders as feedstock, which are vulnerable to oxygen contamination. The primary source for picking up oxygen could be water absorption during powder handling and high-temperature exposure during EBM processing. Many studies have reported that oxygen contamination significantly lowers the creep rupture life and ductility of several Ni-based superalloys [33-37] The excess amount of oxygen in alloys causes oxygen embrittlement through either the formation of brittle oxide particles $[34,35]$ or the diffusion of solute oxygen along the grain boundaries during the creep test [38]. Son et al. [34] reported that AM IN625 had lower creep ductility than C\&W IN625. The poor ductility of AM IN625 is attributable to its high oxygen concentration, which causes the formation of $\mathrm{Al}_{2} \mathrm{O}_{3}$ and eventually leads to oxide particle embrittlement. The presence of oxygen over $140 \mathrm{ppm}$ in powder HIPed IN718 alloy significantly lowers high-temperature ductility and creep-rupture properties by forming deleterious phases such as prior particle boundaries (PPBs) [35]. Furthermore, the solute oxygen diffusion to grain boundaries decreases grain boundary surface energy and promotes grain boundary embrittlement in Ni-based superalloys [39]. In the present study, the EBM IN718 alloy contained $142 \mathrm{ppm}$ of oxygen content, which was substantially higher than the $7 \mathrm{ppm}$ in the wrought alloy. Thus, the relatively higher oxygen content would be one reason for the inferior creep properties of EBM IN718 compared to the C\&W specimen. In addition, the $\mathrm{C} \& W$ specimen had a large fraction of twin boundaries. These would hinder the dislocation motion more effectively during the deformation and allow the accumulation of dislocations within the grains. The evidence of dislocation density after the creep test can be seen in Figure 14. In comparison to the EBM specimen, the C\&W specimen showed a uniform distribution of dislocation density within the grains, which indicates that the twin boundaries beneficial to resisting the dislocation motion within the grains thereby improve the creep resistance.

Moreover, dislocation pile-ups at the twin boundaries in the C\&W specimen act as trapping sites for solute oxygen and decrease the sensitivity of the grain boundary to oxygen embrittlement during creep deformation in air [40]. In conclusion, the superior creep properties of the $C \& W$ specimen relative to the EBM specimen can be explained by the $\mathrm{C} \& W$ specimen's lower amount of oxygen, higher twin boundary fraction, homogeneous grain structure, and $\delta$ precipitate structure.

\section{Conclusions}

The effect of post-heat treatment on microstructure evolution and its relationship with the creep properties of EBM-fabricated IN718 were investigated, and the main conclusions are summarized as follows: 
1. The IN718 fabricated using the EBM process exhibited a columnar-grained structure with a strong $<100>$ crystal orientation along the building direction.

2. The presence of disc-shaped $\delta$ precipitates at the grain boundary and the higher $\gamma^{\prime \prime}$ size in the grain interior are the main reasons for the higher creep life observed in the DA specimen.

3. The creep void formation and coalescence around the needle-shaped $\delta$ precipitates at the grain boundary lead to intergranular fracture in the STA and HSA specimens

4. The lower amount of oxygen, the higher twin boundary fraction, and the homogeneous grain structure are the reasons for the superior creep properties of the $C \& W$ specimen compared to the EBM specimen.

Author Contributions: Conceptualization, T.N.P. and K.K.; data curation, T.N.P., S.B. and Y.-L.K., funding acquisition, K.K.; investigation, T.N.P. and S.B.; methodology, T.N.P. and S.B.; supervision, K.K.; writing-original draft, T.N.P.; writing—review and editing, K.K. All authors have read and agreed to the published version of the manuscript.

Funding: The authors are grateful to the AMADA Foundation (AF-2018222-B3) and the ALCA Program of the Japan Science and Technology Agency, JST (grant number JPMJAL1605) for funding.

Institutional Review Board Statement: Not applicable.

Informed Consent Statement: Not applicable.

Data Availability Statement: The data presented in this study are available on request from the corresponding author.

Conflicts of Interest: The authors declare no conflict of interest.

\section{References}

1. Chaturvedi, M.C.; Han, Y.-F. Strengthening mechanisms in Inconel 718 superalloy. Met. Sci. 1983, 17, 145-149. [CrossRef]

2. Brooks, J.; Bridges, P. Metallurgical Stability of Inconel Alloy 718. Superalloys 1988, 88, 33-42. [CrossRef]

3. Moll, J.H.; Maniar, G.N.; Muzyka, D.R. Heat treatment of 706 alloy for optimum $1200^{\circ} \mathrm{F}$ stress-rupture properties. Met. Mater. Trans. A 1971, 2, 2153-2160. [CrossRef]

4. Lingenfelter, A. Welding of Inconel Alloy 718: A Historical Overview. Superalloys 1989, 718, 673-683.

5. Kakehi, K.; Banoth, S.; Kuo, Y.-L.; Hayashi, S. Effect of yttrium addition on creep properties of a Ni-base superalloy built up by selective laser melting. Scr. Mater. 2020, 183, 71-74. [CrossRef]

6. Gong, X.; Anderson, T.; Chou, K. Review on powder-based electron beam additive manufacturing technology. Manuf. Rev. 2014, 1, 2. [CrossRef]

7. Sochalski-Kolbus, L.M.; Payzant, E.; Cornwell, P.A.; Watkins, T.; Babu, S.; Dehoff, R.; Lorenz, M.; Ovchinnikova, O.; Duty, C. Comparison of Residual Stresses in Inconel 718 Simple Parts Made by Electron Beam Melting and Direct Laser Metal Sintering. Met. Mater. Trans. A 2015, 46, 1419-1432. [CrossRef]

8. Murr, L.; Gaytan, S.; Ceylan, A.; Martinez, E.; Martinez, J.; Hernandez, D.; Machado, B.; Ramirez, D.; Medina, F.; Collins, S Characterization of titanium aluminide alloy components fabricated by additive manufacturing using electron beam melting. Acta Mater. 2010, 58, 1887-1894. [CrossRef]

9. Loeber, L.; Biamino, S.; Ackelid, U.; Sabbadini, S.; Epicoco, P.; Fino, P.; Eckert, J. Comparison of selective laser and electron beam melted titanium aluminides. In Proceedings of the 22nd Annual International Solid Freeform Fabrication Symposium-An Additive Manufacturing Conference SFF, Austin, TX, USA, 8-10 August 2011; pp. 547-556.

10. Strondl, A.; Palm, M.; Gnauk, J.; Frommeyer, G. Microstructure and mechanical properties of nickel based superalloy IN718 produced by rapid prototyping with electron beam melting (EBM). Mater. Sci. Technol. 2011, 27, 876-883. [CrossRef]

11. Goel, S.; Sittiho, A.; Charit, I.; Klement, U.; Joshi, S. Effect of post-treatments under hot isostatic pressure on microstructural characteristics of EBM-built Alloy 718. Addit. Manuf. 2019, 28, 727-737. [CrossRef]

12. Nandwana, P.; Kirka, M.; Okello, A.; Dehoff, R. Electron beam melting of Inconel 718: Effects of processing and post-processing. Mater. Sci. Technol. 2017, 34, 612-619. [CrossRef]

13. Deng, D.; Moverare, J.; Peng, R.L.; Söderberg, H. Microstructure and anisotropic mechanical properties of EBM manufactured Inconel 718 and effects of post heat treatments. Mater. Sci. Eng. A 2017, 693, 151-163. [CrossRef]

14. Kirka, M.M.; Medina, F.; Dehoff, R.; Okello, A. Mechanical behavior of post-processed Inconel 718 manufactured through the electron beam melting process. Mater. Sci. Eng. A 2017, 680, 338-346. [CrossRef]

15. Sun, S.-H.; Koizumi, Y.; Saito, T.; Yamanaka, K.; Li, Y.-P.; Cui, Y.; Chiba, A. Electron beam additive manufacturing of Inconel 718 alloy rods: Impact of build direction on microstructure and high-temperature tensile properties. Addit. Manuf. 2018, 23, 457-470. [CrossRef] 
16. Helmer, H.; Bauereiß, A.; Singer, R.; Körner, C. Grain structure evolution in Inconel 718 during selective electron beam melting. Mater. Sci. Eng. A 2016, 668, 180-187. [CrossRef]

17. Yu, H.; Hayashi, S.; Kakehi, K.; Kuo, Y.-L. Study of Formed Oxides in IN718 Alloy during the Fabrication by Selective Laser Melting and Electron Beam Melting. Metals 2018, 9, 19. [CrossRef]

18. Im, S.-Y.; Jun, S.-Y.; Lee, J.-W.; Lee, J.-H.; Lee, B.-S.; Lee, H.-J.; Hong, H.-U. Unidirectional columnar microstructure and its effect on the enhanced creep resistance of selective electron beam melted Inconel 718. J. Alloy. Compd. 2020, 817, 153320. [CrossRef]

19. Sass, V.; Glatzel, U.; Feller-Kniepmeier, M. Anisotropic creep properties of the nickel-base superalloy CMSX-4. Acta Mater. 1996, 44, 1967-1977. [CrossRef]

20. Kakehi, K. Tension/compression asymmetry in creep behavior of a Ni-based superalloy. Scr. Mater. 1999, 41, 461-465. [CrossRef]

21. Caron, P.; Ohta, Y.; Nakagawa, Y.; Khan, T. Creep Deformation Anisotropy in Single Crystal Superalloys. Superalloys 1988, 1988, 215-224.

22. Mackay, R.A.; Maier, R.D. The influence of orientation on the stress rupture properties of nickel-base superalloy single crystals. Met. Mater. Trans. A 1982, 13, 1747-1754. [CrossRef]

23. Niang, A.; Viguier, B.; Lacaze, J. Some features of anisothermal solid-state transformations in alloy. Mater. Charact. 2010, 61, 525-534. [CrossRef]

24. Sundararaman, M.; Mukhopadhyay, P.; Banerjee, S. Precipitation of the $\delta$-Ni3Nb phase in two nickel base superalloys. Met. Mater. Trans. A 1988, 19, 453-465. [CrossRef]

25. Han, Y.; Chaturvedi, M. Steady state creep deformation of superalloy inconel. Mater. Sci. Eng. 1987, 89, 25-33. [CrossRef]

26. Langdon, T.G. Grain boundary sliding as a deformation mechanism during creep. Philos. Mag. 1970, 22, 689-700. [CrossRef]

27. Han, Y.-F.; Deb, P.; Chaturvedi, M.C. Coarsening behaviour of $\gamma^{\prime \prime}-$ and $\gamma^{\prime}$-particles in Inconel alloy. Met. Sci. 1982, 16, 555-562. [CrossRef]

28. Azadian, S. Aspects of precipitation in alloy Inconel 718. Ph.D. Thesis, Luleå University of Technology, Luleå, Sweden, 2004; pp. 5167. Available online: http://www.diva-portal.org/smash/get/diva2:999089/FULLTEXT01.pdf (accessed on 2 March 2022).

29. Ansell, G.S.; Weertman, S. Creep of a Dispersion-Hardened Aluminum Alloy; Naval Research Lab.: Washington, DC, USA, 1958; p. 838.

30. Chen, W.; Chaturvedi, M. The effect of grain boundary precipitates on the creep behavior of Inconel 718. Mater. Sci. Eng. A 1994, 183, 81-89. [CrossRef]

31. Chen, W.; Chaturvedi, M. Dependence of Creep Fracture of Inconel 718 on Grain Boundary Precipitates. Acta Mater. 1997, 45, 2735-2746. [CrossRef]

32. Kuo, C.-M.; Yang, Y.-T.; Bor, H.-Y.; Wei, C.-N.; Tai, C.-C. Aging effects on the microstructure and creep behavior of Inconel 718 superalloy. Mater. Sci. Eng. A 2009, 510-511, 289-294. [CrossRef]

33. Son, K.-T.; Phan, T.; Levine, L.; Kim, K.-S.; Lee, K.-A.; Ahlfors, M.; Kassner, M. The creep and fracture properties of additively manufactured Inconel. Materials 2021, 15, 101021. [CrossRef]

34. Son, K.; Kassner, M.E.; Lee, K.A. The Creep Behavior of Additively Manufactured Inconel 625. Adv. Eng. Mater. 2020, 22, 1900543. [CrossRef]

35. Rao, G.A.; Srinivas, M.; Sarma, D. Effect of oxygen content of powder on microstructure and mechanical properties of hot isostatically pressed superalloy Inconel. Mater. Sci. Eng. A 2006, 435-436, 84-99. [CrossRef]

36. Nagahari, T.; Nagoya, T.; Kakehi, K.; Sato, N.; Nakano, S. Microstructure and Creep Properties of Ni-Base Superalloy IN718 Built up by Selective Laser Melting in a Vacuum Environment. Metals 2020, 10, 362. [CrossRef]

37. Gessinger, G.H.; Bomford, M.J. Powder Metallurgy of Superalloys. Int. Met. Rev. 1974, 19, 51-76. [CrossRef]

38. Woodford, D.; Bricknell, R. Environmental Embrittlement of High Temperature Alloys by Oxygen. Treatise Mater. Sci. Technol. 1983, 25, 157-199.

39. Huang, Z.; Iwashita, C.; Chou, I.; Wei, R.P. Environmentally assisted, sustained-load crack growth in powder metallurgy nickel-based superalloys. Met. Mater. Trans. A 2002, 33, 1681-1687. [CrossRef]

40. Hayes, R.; Smith, D.; Wanner, E.; Earthman, J. Effect of environment on the rupture behavior of alloys 909 and 718 . Mater. Sci. Eng. A 1994, 177, 43-53. [CrossRef] 